\title{
Ruptured intracranial dermoid cyst
}

Sir

Intra-axial dermoid cysts are rare intracranial lesions, more so in the pediatric age group. Dermoid cysts account for about 0.2 to $1.8 \%$ of all intracranial tumors and are commonly located in the cisternal spaces, mainly in the cerebellopontine angle and parasellar 


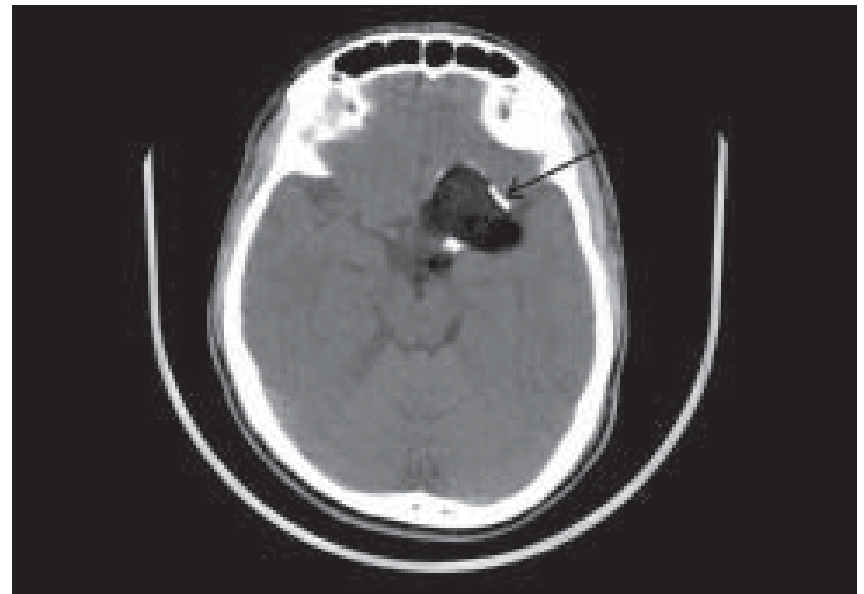

Figure 1: Well-defined round hypodense mass with attenuation consistent with fat and peripheral calcification (black arrow)

cisterns. ${ }^{[1]}$ Intracranial dermoid cysts are pathologically characterized by a thick, stratified squamous epithelium cyst wall containing dermal elements. ${ }^{[2]}$ Rupture of dermoid cyst can cause granulomatous chemical meningitis that can result in recurrent symptoms, most commonly headache. Headache is often the presenting feature of ruptured intracranial dermoid. Rupture of dermoid cyst is unusual to present in older people. ${ }^{[3]}$

Rupture of an intracranial dermoid produces a dramatic MR and CT appearance. ${ }^{[4]}$ Computerized tomography (CT) scan typically shows a well-defined round hypodense mass lesion with attenuation consistent with fat and peripheral calcification [Figure 1]. In case of ruptured dermoid cyst, CT scan shows low-density fatty droplets scattered throughout the ventricles and subarachnoid space [Figure 2]. A fat-cerebrospinal fluid (CSF) level may also be seen. Dermoid cysts do not enhance on contrast administration. The presence of disseminated fat droplets in the subarachnoid space or ventricles on neuroimaging is diagnostic for a ruptured dermoid cyst. ${ }^{[5]}$ A definitive diagnosis can be made by the characteristic features on CT $\operatorname{scan}^{[6]}$ Magnetic resonance imaging typically demonstrates high signal intensities on T1 and variable signal intensities on T2. This is consistent with the lipid and cholesterol which typically collects within the dermoid cyst. When the

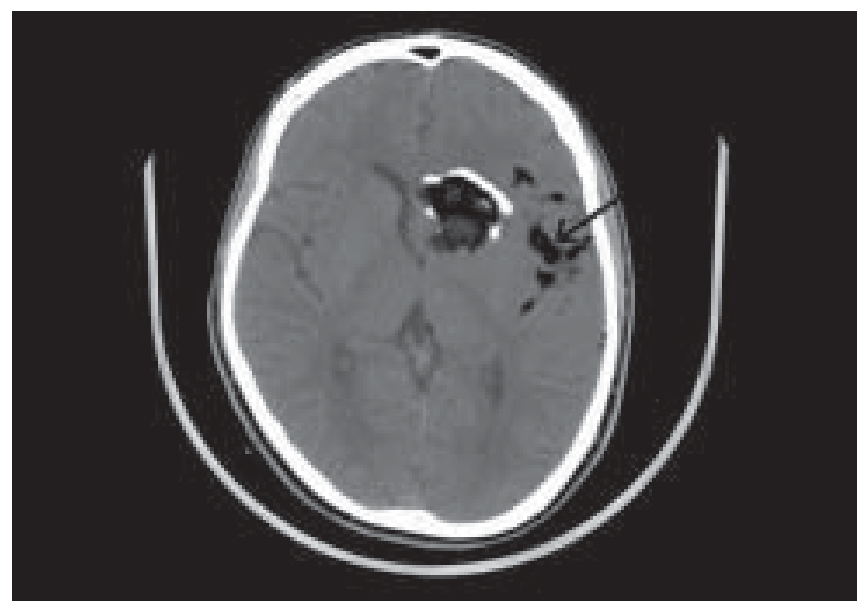

Figure 2: Scattered low-density fatty droplets may be scattered in the subarachnoid spaces suggestive of rupture (black arrow)

cyst ruptures, high-signal droplets on T1 images may be seen scattered throughout the CSF. Sometimes a fatCSF fluid level may also be seen

Santosh P. V. Rai

Department of Radiodiagnosis, KMC Hospital, Attavar, Mangalore - 575 001, Karnataka, India. E-mail: radiorai@gmail.com

DOI: $10.4103 / 0028-3886.48803$

\section{References}

1. Pant I, Joshi SC. Cerebellar intra-axial dermoid cyst: A case of unusual location. Childs Nerv Syst 2008;24:157-9.

2. Liu JK, Gottfried ON, Salzman KL, Schmidt RH, Couldwell WT Ruptured intracranial dermoid cysts: Clinical, radiographic, and surgical features. Neurosurgery 2008;62:377-84.

3. Rajapakse A, Diack A. Ruptured intracranial dermoid: An unusual cause of headache in an older patient. Headache 2008;48:294-6.

4. Stephenson TF, Spitzer RM. MR and CT appearance of ruptured intracranial dermoid tumors. Comput Radiol 1987;11:249-51.

5. Das CJ, Tahir M, Debnath J, Pangtey GS. Neurological picture: Ruptured intracranial dermoid. J Neurol Neurosurg Psychiatry 2007;78:624-5.

6. Amendola MA, Garfinkle WB, Ostrum BJ, Katz MR, Katz RI Preoperative diagnosis of a ruptured intracranial dermoid cyst by computerized tomography: Case report. J Neurosurg 1978;48:1035-7.

Accepted on 21-01-2009 